\title{
El Archivo del Seminario Metropolitano San Atón de Badajoz: organización de sus fondos documentales
}

\author{
The Archive of the Saint Aton's Metropolitan Seminary (Badajoz, Spain): organization of its archival holdings
}

\section{María Guadalupe PÉrez ORTIZ, Francisco GonzÁLEz LozANo}

\author{
Seminario Metropolitano de san Atón. 06006 Badajoz, mgperort@alcazaba.unex.es, fglozano@hotmail.com
}

\section{Resumen}

El archivo del Seminario Metropolitano de San Atón en Badajoz custodia la documentación generada y recibida por esta entidad en el transcurso de su actividad pedagógica, pastoral y litúrgica, la cual se remonta a mediados del siglo XVII. Se discute la historia de la entidad, el valor la documentación custodiada, y sus principales contenidos. Se detalla la construcción del cuadro de clasificación y el proceso de descripción, basado en la norma ISAD $(G)$. Se destaca la riqueza documental custodiada en este centro para el estudio de variados temas, muy especialmente los relacionados con la educación y la cultura en Extremadura desde los siglos XVII-XIX.
\end{abstract}

Palabras clave: Seminario de San Atón (Badajoz, España). Archivos eclesiásticos. Archivos de seminarios. Clasificación documental. Investigación histórica.

\section{Introducción}

Según consta en el Libro de Fundación del Seminario (Seminario..., 1664-1672, fol. 12), el tres de mayo de mil seiscientos sesenta y cuatro, se nombraron los primeros colegiales, se les impusieron las becas y, junto al Rector, entraron en el que será el "Seminario Conciliar de San Atón". Han pasado trescientos cincuenta años de este singular acontecimiento tanto para la Iglesia como para la cultura extremeña. Durante el año 2014, el Seminario Metropolitano San Atón de Badajoz está conmemorando este aniversario fundacional. Nos mueve a ello la herencia educativa recibida y el deseo de resaltar su impronta en la historia eclesiástica y cultural extremeña.

Al volver la mirada atrás, hacemos un recorrido histórico homenajeando a la función formativa que esta institución eclesial ha ejercido para el servicio no sólo de la Iglesia, sino de la educación extremeña. La influencia en el devenir histórico y cultural extremeño del Seminario ha sido de capital importancia; miles de niños y jóvenes, desde hace casi cuatro siglos, han forjado su personalidad y han aportado su ma-

\begin{abstract}
The archive of the Metropolitan Seminar of San Aton in Badajoz guards the records generated and received by this entity in the course of its pedagogic, pastoral and liturgical activity, which goes back in the middle of the $17^{\text {th }}$ century. The history of the seminary, the value of its documentation, and its main contents are discussed. The construction of the classification and the description process, based on ISAD $(G)$, are also detailed. The documentary wealth guarded in this center for the study of varied topics is highlighted, especially related to the history of education and the culture in Extremadura from the $17^{\text {th }}$ to the $19^{\text {th }}$ century.
\end{abstract}

Keywords: Seminary of San Atón (Badajoz, Spain). Ecclesiastic records. Seminary archives. Archival classifications. Historical research.

duración al contexto - pasado, presente y futuro- sociocultural y religioso en el que se han insertado, bien como sacerdotes, bien como hombres al servicio de la sociedad.

Su Archivo, fuente que custodia la vida de la entidad por medio de la conservación de sus documentos, da suficiente prueba del sello impreso en la vida extremeña. La documentación existente nos permite conocer la intrahistoria y el devenir del Seminario, siendo fuente documental de primer orden en la investigación pasada y futura.

Los archivos eclesiásticos registran el camino seguido a lo largo de los siglos por la Iglesia en cada una de las realidades que la componen. Ya que éstos son los lugares visibles de la memoria de la Iglesia, deben recoger sistemáticamente los datos con los que se ha escrito la historia de la comunidad eclesial, para que ofrezcan la posibilidad de una atenta valoración de lo que se ha realizado, de los resultados obtenidos, de las omisiones y errores (Pontificia..., 1997). En líneas generales, encontramos varias clasificaciones en relación a los archivos eclesiásticos. Algunas son similares, sin embargo hay otras con importantes diferencias que se 
deben, en cierto modo, al momento en el que fueron llevadas a término y no a cuestiones estructurales. Debemos reseñar que en estas categorizaciones se utilizan diferentes criterios de clasificación archivísticos, hecho vital que da lugar a segmentaciones en las que se aprecian desacuerdos. En ningún caso se trata de clasifi- caciones contradictorias sino concordantes en la diversidad de criterios y además, no se trata de clasificaciones excluyentes sino que admiten criterios incorporados. Todas ellas, pues, son válidas y aprovechables. Exponemos a modo de tabla algunas de ellas (Tabla I).

\begin{tabular}{|c|c|c|c|c|c|c|c|}
\hline $\begin{array}{l}\text { C. Derecho } \\
\text { Canónico } \\
(1917)\end{array}$ & $\begin{array}{l}\text { Nunciatura } \\
\text { (1929) }\end{array}$ & $\begin{array}{c}\text { Dicc. Historia } \\
\text { Eclesiástica } \\
\text { (Aldea Et Al., } \\
1972 \text { ) }\end{array}$ & $\begin{array}{l}\text { C. Derecho } \\
\text { Canónico } \\
(1983)\end{array}$ & $\begin{array}{c}\text { Dicc. } \\
\text { Patrimonio } \\
\text { Cultural } \\
\text { (Iguacén, } \\
\text { 1999) }\end{array}$ & $\begin{array}{c}\text { Asociación } \\
\text { Archiveros } \\
\text { de la Iglesia } \\
\text { (1997) }\end{array}$ & $\begin{array}{c}\text { Manual de } \\
\text { Archivos (Rubio, } \\
\text { 1999) }\end{array}$ & $\begin{array}{c}\text { Guía de Archivos de } \\
\text { la Iglesia } \\
\text { (Bonet, 2001) }\end{array}$ \\
\hline Diocesano & Diocesano & & Diocesano & Diocesano & Diocesano & Diocesano & Histórico/Diocesano \\
\hline Catedral & Catedral & Catedral & Catedral & Catedral & Catedral & Catedral & Catedralicio \\
\hline Parroquial & Parroquial & Parroquial & Parroquial & Parroquial & Parroquial & Parroquial & Parroquial \\
\hline \multicolumn{8}{|l|}{ Histórico } \\
\hline Secreto & & & Secreto & Secreto & & & \\
\hline Colegiata & & & Colegiata & Colegiata & & & \\
\hline \multirow[t]{9}{*}{ Fundaciones } & Fundaciones & & & & & & \\
\hline & Monacal & Monacal & & & Monacal & Monacal & Monástico \\
\hline & & Vaticano & & & & & \\
\hline & & Seminario & & & Seminario & Seminario & Seminario \\
\hline & & Santa Cruzada & & & & & \\
\hline & & & & C. Episcopal & & & C. Episcopal \\
\hline & & & & & Hospitales & & \\
\hline & & & & & Asoc. fieles & & \\
\hline & & & & & & Órd. activa & Órd. activa \\
\hline
\end{tabular}

Tabla I. Tipología de Archivos Eclesiásticos: clasificaciones

Si nos centramos en la tipología archivística en la que se encuadra el archivo analizado, es decir, un archivo de seminario, podemos observar cómo no aparece en todas las clasificaciones expuestas, aunque bien es cierto, que está presente en las clasificaciones más actuales, especialmente la que aglutina el mayor número de archivos y archiveros eclesiásticos, como es la formulada por la Asociación de Archiveros de la Iglesia Católica.

Se convierte ahora en una cuestión primordial entender, al menos someramente, qué es un seminario y porqué en un determinado momento de nuestra historia, allá por el siglo XVI, surgen estas entidades como herramienta para solventar ciertas carencias que se estaban haciendo excesivamente notorias dentro de la Iglesia católica. Únicamente de este modo podremos clasificar a posteriori la documentación generada por este tipo de instituciones.

\section{El Concilio de Trento (1545-1563) y el nacimiento de los seminarios}

En los primeros siglos de la Iglesia, los obispos recorrían sus diócesis en busca de jóvenes que estuvieran al servicio del Pueblo de Dios. Cómo fue y se llevó a cabo su formación no nos cons- ta detalladamente; sí sabemos que más allá de una formación reglada, consistía en afirmar a Cristo y en despojarse del hombre viejo para ser imagen del Buen Pastor. A partir del siglo II surgen las escuelas catequéticas, que encontrarán, a partir del 313, su organización definitiva, proporcionando una instrucción religiosa, una preparación ascética, y la recepción de los sacramentos del Orden a los alumnos aptos que serían elegidos como maestros y sacerdotes. Los concilios de Nicea (325), Constantinopla (381), Éfeso (431) y Calcedonia (451) sustentarán esta formación. Dichas escuelas estarán vigentes hasta el siglo $\mathrm{V}$.

La caída del Imperio romano y la situación de la Iglesia como única fuente sólida de principios morales y religiosos fue dando paso a la creación de escuelas catedralicias. El concilio II de Toledo (527), en su canon II hacía hincapié en la dimensión formativa seria y el carácter diocesano de estas escuelas episcopales.

Empezamos a encontrar antecedentes muy similares a los actuales seminarios durante los siglos posteriores; así, en el concilio I de Aquisgran, celebrado en el 816, ya localizamos las líneas directrices de estas futuras instituciones (Concilium Aquisgranense, I, 135). Tras la re- 
forma cluniacense florecen las escuelas catedralicias. El III Concilio de Letrán dispuso en 1119 que en todas las catedrales existiera la figura del maestrescuela (Brown, 1990).

El nacimiento de una nueva institución orientada a la formación de los clérigos nos conduce directamente a la situación de la Iglesia católica en un periodo de confusión doctrinal provocada por las teorías de Lutero, Calvino y Zwinglio. La teología católica comenzaba a resquebrajarse, por lo que fue necesario un impulso a la formación sacerdotal. Así pues, los seminarios nacieron a raíz del Concilio de Trento (1545-1563) como centros para atender la formación del clero, que en el siglo XVI era un tanto escasa. En concreto en la sesión XXIII del Concilio (Concilium..., 1901, ses. 23, can. 18 de reformatione), que se desarrolló desde el 15 de julio de 1563 al 11 de noviembre de 1563, se aborda, junto con la doctrina sobre el Sacramento del Orden, la creación de seminarios para los clérigos y se dispone que las catedrales fueran las que se encargaran de su fundación y consolidación.

Establece el santo Concilio que todas las catedrales, metropolitanas e Iglesias mayores, tengan obligación de mantener y educar religiosamente, e instruir en la disciplina eclesiástica, según las posibilidades y extensión de las diócesis, cierto número de jóvenes de la misma ciudad y diócesis, o, a no haberlos en ésta, de la misma provincia, en una colegio situado cerca de las mismas Iglesias, o en otro lugar oportuno, a elección del obispo [...] Cuide el obispo que asistan todos los días al sacrificio de la Misa, que confiesen a los menos una vez al mes, que reciban, a juicio del confesor, el Cuerpo de nuestro Señor Jesucristo, y que sirvan en la catedral y en otras Iglesias del pueblo los días festivos. El obispo [...] arreglará, según el Espíritu Santo le iluminare, todo lo dicho, y todo cuanto sea oportuno y necesario, velando en sus frecuentes visitas de que siempre se guarde [...]

Las reflexiones del Concilio nos acercan a un clero que se presentaba frágil intelectualmente hablando. De esta manera se decreta la creación y la obligatoriedad de los seminarios sacerdotales en las diócesis, lo cual es confirmado por el Papa Pío IV (Rops, 1970, vol. 7, 104 ss.). Durante la segunda mitad del siglo XVI y hasta finales del siglo XVII, la aplicación del decreto conciliar fue urgida por Sínodos particulares, obispos y sacerdotes. A pesar de ello, en la Diócesis de Badajoz, al igual que en las otras diócesis extremeñas, los sínodos celebrados antes de Trento muestran ya la preocupación por la instrucción de los clérigos, como consta en el de 1501 (García García, 1990):

De las cosas que los sacerdotes especialmente han de saber e de examinacion que se les debe hazer quando se les diere licencia para decir misa. Al oficio de los sacerdotes pertenece estudiar y procurar de saber las quizás que son obligados así para instrucción como para doctrina del pueblo a quien deben enseñar [...]

La primera mitad del siglo XVIII se caracteriza por asentar las bases de una reforma en el seno de la Iglesia que se consolidará durante el reinado de Carlos III y Carlos IV y que afectará, sin igual, a los seminarios. Si la Iglesia española, ha conocido momentos de renovación, quizás los que acontecieron en el siglo XVIII fueron los más significativos, especialmente si miramos al seminario, cuando a medio hacer la universidad moderna, y diluidos los colegios universitarios, éstos llegan a ser epicentro de la vida educativa. Mientras en España se iban desarrollando variados sucesos, como la expulsión de los Jesuitas, el monarca Carlos III emite una Real Cédula, el 14 de agosto de 1768, para regular y reformar los seminarios. Con Carlos IV, se pretende continuar con la dinámica iniciada con su antecesor. A pesar de todo, había llegado ya la decadencia de estas instituciones que no consiguieron más que prometerse esperanzadoras. Durante la primera mitad del siglo XIX la acción combinada de los obispos y del Estado hizo que la renovación fuera posible (Martín Hernández, 1959).

\subsection{Los archivos de seminarios: características y tipologías generales}

La archivística eclesiástica se ha visto envuelta a lo largo de los tiempos por una serie de problemáticas que obstaculizaban un desarrollo global de la materia. Al centrarnos en los archivos de seminarios este hecho se hace más palpable, abordándose la materia casi de una forma tangencial. A pesar de la inexistencia de obras que estudien de forma específica los archivos de estas instituciones, que dificulta enormemente un acercamiento integral a sus fondos; es cierto, que podemos acceder a una interesante bibliografía sobre estas entidades a nivel general y es en ella, donde podremos consultar cuestiones relativas a sus bibliotecas y archivos (Altamira, 1943; Anasagasti, 1915; Blanco Cotano, 1998; Díaz, 1991; García Hernando, 1959; Hernández Corrales, 1992; Hernández Figueiredo, 2004; Mansilla Reoyo, 1954; Pérez López, 1987; Rubio Merino, 1964).

\subsubsection{Cuadro de clasificación para archivos de seminarios: propuesta de trabajo}

Exponemos a continuación un cuadro de clasificación diseñado para los archivos de seminarios siguiendo las pautas del reconocido archivero eclesiástico don Pedro Rubio Merino (1999) 
ofrecidas en su manual, el cual es todavía un claro referente en materia de archivos de la Iglesia. Se trata, por tanto, de un modelo general y como tal deberá ser modificado y adaptado a las necesidades específicas de cada archivo.

\author{
1.0 ENSEÑANZA \\ 1.01 Alumnado \\ 1.01.01 Agregación de estudios \\ 1.01.02 Grados \\ 1.01.03 Informaciones \\ 1.01.04 Registro de notas \\ 1.02 Profesorado \\ 1.02.01 Actas de claustro \\ 1.02.02 Expedientes de profesores \\ 1.02.03 Libros de acuerdo \\ 1.02.04 Nóminas \\ 2.0 GOBIERNO \\ 2.01 Correspondencia \\ 2.01.01 Cartas al prelado \\ 2.01.02 Otras cartas \\ 2.02 Contabilidad \\ 2.02.01 Cuentas alumnado \\ 2.02.02 Cuentas cargo y data \\ 2.03 Documentación del prelado \\ 2.03.01 Cargos \\ 2.03.02 Decretos \\ 2.03.03 Doctrina \\ 2.04 Documentación Interna \\ 2.04.01 Constituciones \\ 2.04.02 Estatutos \\ 2.04.03 Reglamentos \\ 3.0 ORDENES SAGRADAS \\ 3.01 Ordenaciones \\ 3.01.01 Expedientes ordenaciones \\ 3.01.02 Liturgia de ordenación \\ 4.0 PATRIMONIO \\ 4.01 Becas \\ 4.01.01 Adjudicaciones de becas \\ 4.02 Colectas \\ 4.01.02 Solicitudes de beca \\ 4.02.01 Donaciones \\ 4.02.02 Inventario de bienes \\ 4.02.03 Testamentos
}

Tabla II. Propuesta de clasificación de archivos de seminarios (Rubio, 1999)

\subsubsection{Análisis de series documentales}

El cuadro de clasificación que exponemos se estructura en cuatro secciones que atienden a cada uno de los aspectos constitutivos de los seminarios: enseñanza, gobierno, sacramento del Orden y patrimonio.

1. Enseñanza. Esta primera sección da cabida a los aspectos relacionados con la vertiente educativa y pedagógica de los seminarios. No debemos olvidar que una de las cuestiones fundamentales por las que se crean estas instituciones fue para atender la vertiente formativa de los jóvenes con aspiraciones al sacerdocio. Estructurada en dos subsecciones.
La primera subsección, alumnado (1.01), documentación relativa a los seminaristas en su vertiente académica exclusivamente. Está integrada por cuatro series:

- Agregación de estudios (1.01.01): expedientes académicos de seminaristas que en algún momento de su formación cursaron estudios en centros universitarios o fueron agregados a alguna universidad tradicional. Era usual este "intercambio" de alumnos entre instituciones.

- Grados (1.01.02): certificado que se otorgaba a los seminaristas tras la finalización de sus estudios teologales.

- Informaciones (1.01.03): expediente académico que de cada alumno se iba elaborando curso tras curso, reflejando notas y otros aspectos, destacables o no, de su vida académica.

- Registro de notas (1.01.04): libro donde se inscriben las notas de los alumnos que estudian en el seminario. En la antigüedad las calificaciones eran publicadas anualmente por el obispo para el conocimiento de otros sacerdotes y de la diócesis.

La segunda subsección, profesorado (1.02), da cabida a la documentación sobre profesores que imparten clases en los seminarios. Se constituye por cuatro series documentales:

- Actas de claustro (1.02.01): recopilación de los puntos más significativos tratados en las reuniones que los profesores mantenían periódicamente con el fin de mejorar los aspectos docentes del centro.

- Expedientes de profesores (1.02.02): informe de la vida académica y profesional de cada uno de los docentes que imparten clases en estos centros.

- Libros de acuerdos (1.02.03): registros en los que se anotan las resoluciones emanadas de los claustros de profesores.

- Nóminas (1.02.04): registro de los pagos efectuados a los profesores por el ejercicio de sus competencias docentes.

2. Gobierno. Esta segunda sección está relacionada con la gestión de cada uno de los aspectos constitutivos de los seminarios, es por tanto, de vital importancia para el conocimiento exhaustivo de estas instituciones dado que abarca aspectos intrínsecos de las mismas. Ha quedado divida en cuatro subsecciones: 
La primera subsección, correspondencia (2.02), se presenta dividida en dos series documentales:

- Cartas al prelado (2.01.01): La comunicación directa entre los seminarios y el obispo y viceversa es muy frecuente dentro de los seminarios. Por ello, se constituye una serie documental independiente. El prelado tenía la misión de adoctrinar a los seminaristas, además de controlar el buen funcionamiento de los seminarios; por ello, esta serie documental suele estar constituida de un amplio volumen de documentos de variada índole.

- Otras cartas (2.01.02): Bajo esta serie documental se custodiará el resto de correspondencia que llega al seminario. Es una serie muy heterogénea, que da lugar en algunos archivos a establecer varias subseries para intentar homogeneizarla.

La segunda subsección, contabilidad (2.02), abarcará la documentación económica surgida de la gestión diaria del seminario. Se presenta dividida en dos series documentales, aunque pudieran establecerse otras dependiendo de cada caso particular:

- Cuentas de alumnado (2.02.01): documentación en la que se reflejan los pagos que los alumnos hacen al seminario. Generalmente estos pagos eran de dos tipos: manutención y enseñanza.

- Cuentas de cargo y data (2.02.02): Es el diario económico del seminario dado que en él se registran los ingresos y pagos que la entidad efectúa diariamente.

La tercera subsección, documentación del prelado (2.03), se integra de la documentación relacionada con la intervención del prelado en las actividades y marcha del centro. Está constituida por tres series documentales:

- Cargos (2.03.01): documentación sobre nombramientos de rectores, formadores, personal docente y otros cargos destinados a impartir formación en el seminario.

- Decretos (2.03.02): disposiciones emitidas por el obispo para ser llevadas a término en estos centros con el fin de mejorar alguna cuestión específica.

- Doctrina (2.03.03): Además de la formación académica, los seminaristas para desempeñar su futuro papel sacerdotal requieren de un adoctrinamiento teológico y pastoral. El obispo como cabeza de la jerarquía eclesiástica diocesana participa activamente de esta formación por medio de comunicaciones, informes, cartas, etc.

La cuarta subsección, documentación interna (2.04), se constituye de tres series documentales:

- Constituciones (2.04.01): Abarca las leyes básicas de la entidad en la que quedan definidos derechos, libertades, poderes, competencias, etc. de cada seminario.

- Estatutos (2.04.02): Son las disposiciones bajo las que se constituyen estos centros docentes, así como las pautas que les servirán de guía para su mejor funcionamiento.

- Reglamentos (2.04.03): conjunto de preceptos formulados para el mejor rendimiento de los seminarios.

3. Órdenes Sagradas. Esta tercera sección está relacionada con la recepción del sacramento del Orden, a la que los seminaristas llegan tras su periodo formativo en los seminarios. Se integra de una única subsección.

La subsección ordenaciones (3.01), abarca la documentación generada en este proceso. Se constituye de dos series documentales:

- Expedientes de ordenación (3.01.01): certificados que constatan el término del proceso formativo y doctrinal de los seminaristas recibiendo el sacramento del Orden.

- Liturgia de ordenación (3.01.02): material eclesiástico utilizado para la preparación de los futuros sacerdotes para la recepción del Orden, así como la documentación utilizada para el desarrollo de dicho proceso.

4. Patrimonio. Esta cuarta sección expone la documentación relacionada con la administración del patrimonio del seminario, integrado por propiedades urbanas, rústicas, valores mobiliarios, piezas de arte, etc. No debemos olvidar que tiempo atrás, muy especialmente en los siglos XVII y XVIII, los seminarios fueron receptores de múltiples bienes por medio de testamentos y mandas pías. Queda constituida por dos subsecciones:

La primera subsección, becas (4.01), hace alusión a las ayudas económicas que se concedían para que los seminaristas pobres o con escasos recursos pudieran cumplimentar sus estudios. Se integra de dos series documentales:

- Adjudicaciones de becas (4.01.01): documentos en los que se hace constar el seminarista al que se le ha concedido una beca, así como el tipo de beca concedida. 
- Solicitudes de becas (4.01.02): documentos en los que, el seminarista o futuro seminarista, reclama ser benefactor de una ayuda para poder cursar estudios en un determinado centro.

La segunda subsección, colectas (4.02), se refiere a la administración de los donativos que por vía ordinaria o campaña extraordinaria llegaban al seminario. Queda constituida por tres series documentales:

- Donaciones (4.02.01): Los seminarios, especialmente en el siglo XVIII, fueron favorecidos por medio de esta vía. Eran muchas las familias que dotaban a estos centros de bienes muebles e inmuebles para su mejor subsistencia y desarrollo.

- Inventario de bienes (4.02.02): relación de propiedades patrimoniales de las que un seminario dispone.

- Testamento (4.02.03): cláusulas testamentarias que favorecen a la entidad dotándola de recursos de los que hasta el momento no era poseedora. Era común que los sacerdotes legaran por testamento parte de sus bienes a la entidad que les formó. También familias cristianas legaban parte de sus bienes a los seminarios. Hoy por hoy, es una práctica que no ha dejado de efectuarse, aunque el número de bienes que llegan a los seminarios por esta vía es considerablemente menor que en épocas pasadas.

Según nos aporta el anterior cuadro de clasificación, los archivos de seminarios legan a la historia eclesiástica una documentación única, la que concierne a la etapa previa al sacerdocio, marcada por aspectos doctrinales y educativos que convierten a estos archivos en fuentes de documentos de singular relevancia, especialmente relacionados con la educación y la pedagogía, puesto que fueron centros de referencia a nivel educativo. Por todo ello, son habituales desde hace algún tiempo, desde la Iglesia católica, las tareas de ordenación y clasificación de estos fondos que, sin lugar a duda, darán a conocer un riquísimo patrimonio documental que hasta la fecha estaba relegado a desaparecer entre los muros de estas entidades. Estas tareas, a las que nos referimos en líneas anteriores, se han llevado a término durante más de un año en el Seminario Metropolitano San Atón de Badajoz. Los trabajos acometidos en su archivo han dado ya sus primeros frutos, que se han visto plasmados en una guía/inventario del archivo que va a ser de gran utilidad a los investigadores. Por ello, nos centraremos en el tercer epígrafe de este estudio en el Seminario de San
Atón desde su vertiente histórica y fundamentalmente archivística como principal productora de la documentación custodiada en su archivo.

\section{Aproximación a la historia del Seminario Metropolitano San Atón de Badajoz}

El tiempo y los estudios históricos constatan que la creación de los seminarios no fue un hecho inmediato a la promulgación de los decretos tridentinos. Una de las razones por las que se retrasó el inicio de estas instituciones fue la coexistencia con colegios y universidades. La universidad española gozaba de gran prestigio y entorno a ella surgieron estos centros universitarios que hicieron las veces de seminarios (Blanco, 1948; Fernández Conde, 1948, p. 2122). Otras razones que impidieron la inmediata fundación de los seminarios fueron la pobreza de las diócesis y la resistencia de algunos cabildos catedralicios que habían llevado la dirección de las escuelas catedralicias que antaño cumplieron funciones formativas. A estas cuestiones que afectaban a la Iglesia católica, le sumamos una situación particular que atañe a la diócesis pacense, a saber, el cambio de los obispos de la sede, que dificultaba el inicio de un proyecto tan ambicioso como la creación de esta institución educativa.

La ciudad de Badajoz se ve inmersa en esta situación durante un largo periodo. Por ello, el rey Felipe II tuvo que recordar a nuestro cabildo, entre otros, en 1594, que habían pasado más de treinta años desde la celebración del Concilio y que no se había hecho nada al respecto para la constitución del seminario. Veamos literalmente sus palabras (A.C.B. Cartas Reales, Tomo $\left.1^{\circ}, n^{\circ} 20\right)$ :

[...] avía mas de treinta / años que el concilio se avía publicado y esta obra..., tan neçesaria y conveniente / para todo el Reyno por la utilidad que resultaría de que los niños se criasen en / buena doctrina y costumbres y letras, no se avía executado ni cumplido", por lo que ruega y encarga a la corporación capitular "que dentro de veinte días primeros siguientes después / que os fuera mostrada -la carta- enviéis ante los del nuestro consejo relación, en manera que / haga fee, si en esse obispado se a hecho el dicho seminario por la orden que por el / sanctoconçilio se dispone y quánto a que se hiço y qué renta se le applicó.

La escasez de beneficios y rentas obligaron al cabildo pacense a dilatar en el tiempo la creación de nuestro seminario, aunque la exigencia conciliar había encontrado eco en alguno de los prebendados de la catedral de Badajoz. Lo pone de manifiesto el testamento del canónigo don Rodrigo Dosma Delgado. En dicho testamento, otorgado el 8 de mayo de 1588, sus bienes 
quedaban vinculados a favor de la descendencia que tuviera su hermano, siguiendo como beneficiarios los sucesores de la misma; pero, faltando tal descendencia y sucesores, las dos terceras partes de tales bienes pasarían al que fuera "seminario que se erija en las casas grandes de mi morada" y si tal seminario hubiera sido erigido antes de que tales bienes quedaran desvinculados era voluntad de nuestro canónigo que, producido este hecho, pasase de inmediato a sus casas (Barrantes, 1870). Al principio existieron problemas con los herederos directos del canónigo, que tuvo que refrendar el obispo don Jerónimo Rodríguez de Valderas (1662-1668), consiguiendo que el seminario se instaurara en la casa del fallecido canónigo en el año 1664 y estableciendo que fuera primer rector del mismo, el licenciado don Juan López Jaramillo. Permaneció el seminario en estas instalaciones, muy próximas a la catedral, durante algún tiempo. Posteriormente, y debido a las necesidades de espacio y gracias las negociaciones del obispo don Amador Merino Malaguilla (17301755) se compran unas casas y después de unas profusas obras se traslada el seminario a la plaza de Minayo, el 26 de octubre de 1754, entonces Campo de San Francisco. En este momento es rector del seminario don José González Vaca.

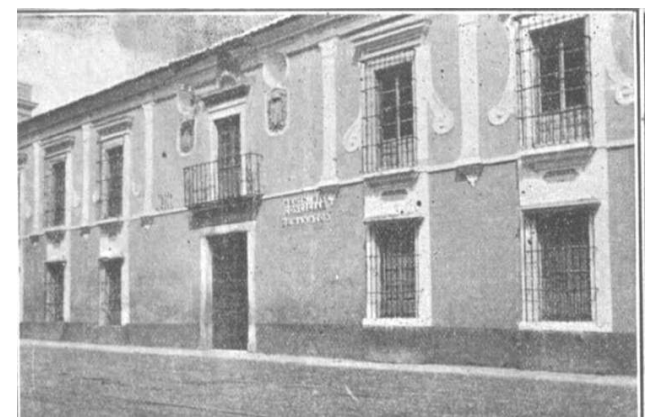

Figura 1. Antigua sede del Seminario de Badajoz

El paso del tiempo y las nuevas circunstancias a las que el seminario tuvo que ir adaptándose, obligaron a plantearse que las dependencias que estaba ocupando no eran las más idóneas, en medio del bullicio de una ciudad. Por ello, el entonces obispo don Ramón Pérez Rodríguez se decidió a buscar unas nuevas instalaciones alejadas del centro. Una vez que solventó los trámites legales, el obispo y el cabildo pacense adquirieron una amplia huerta en la Cañada de Sancha Brava y comenzaron la construcción del nuevo edificio. Tras las obras, en las navidades del año 1927, se sitúa el seminario de Badajoz en este nuevo edificio en el que se encuentra actualmente.

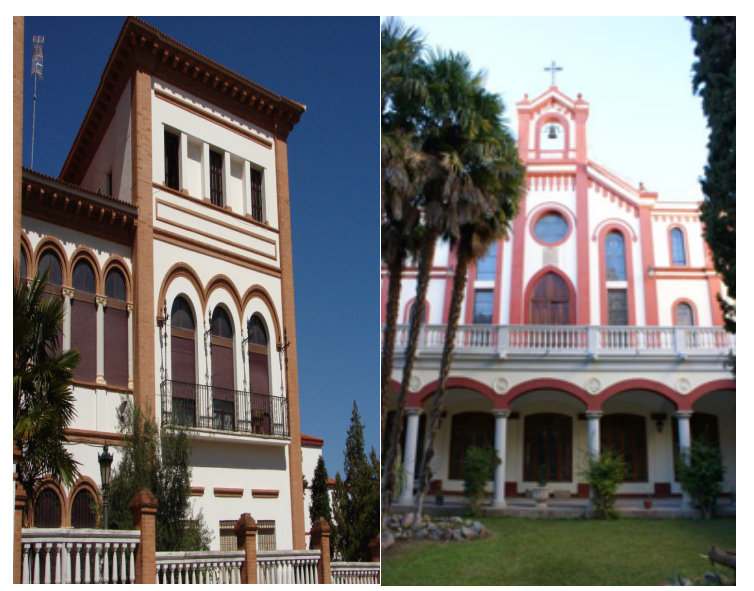

Figura 2. Dependencias actuales del Seminario San Atón

\subsection{El Archivo del Seminario Metropolitano san Atón de Badajoz}

El Archivo del Seminario de San Atón se crea a la vez que se instituye el Seminario, el 26 de Mayo de 1664, siendo obispo de la diócesis de Badajoz, Don Jerónimo Rodríguez de Valderas, según consta en las Constituciones que se aprobaron para la vida cotidiana del centro, en el Título 27 de las mismas.

En el lugar y parte que para este efecto de ser Archibo, se señalare, se pondrán tres cerraduras y llaves diferentes, las quales se tendrán las mismas personas, que esta dicho han de tener las del Arca: $Y$ en casso que qualquiera de ellas enfermare o hiciere ausencia del Colegio entregará unas y otras en presencia de la Capilla al que le hubiere de suceder en el oficio.

En el dicho Archibo se han de guardar todos los papeles pertenecientes a la fundación y erección del Colegio; los Titulos de las Uniones y agregaciones de los Beneficios Simples y los de qualesquiera otra hacienda y Vienes que finalmente todos los papeles necesarios para guarda del derecho del Colegio. $Y$ anssimesmo se pondrán las quentas que el Prelado tomare de la Hacienda del Colegio con todos los recaudos, para su verificación se presentaron.

$Y$ tendrasse un libro dentro del dicho Archibo en que aya razón de todos los Papeles que en el hubiere y de los que se sacaren con dia, mes y año y firma del que los recibiere para que le vuelva o de razón del.

$\mathrm{Ha}$ de haver otro libro en que se escriban las entradas de Rectores y Colegiales, y de cómo juraron con día, mes y año y los traslados de las probissiones que pressentaren. En otro libro se escriban las ausencias que el Rector y Colegiales hicieren, y con qué licencia, por quanto tiempo, y ansi mismo se escriba el día que bolbieron.

El archivo está formado por la documentación producida y recibida por el Seminario de San 
Atón y otras instituciones educativas (dependientes de él y las que, posteriormente, se agregaron a él, hoy todas ellas desaparecidas), en el trascurso de su actividad académica y pastoral. Dividido en tres secciones, de acuerdo a las Constituciones del centro y al Reglamento interno; así como a la reglamentación canónica. El documento más importante por su valor histórico es el Libro Fundacional (1664), que incluye las primeras constituciones del Seminario; si bien el documento más antiguo es una escritura de censo de 1464, de las obras pías que se agregaron a él para su mantenimiento.

El fondo histórico contiene un total de 140 libros y 131 cajas/papel-pergamino. Mientras que el archivo intermedio, pendiente de organización y clasificación, ronda las 300 cajas. La consulta del fondo documental es libre y gratuita, restringida en lo referente al derecho de intimidad y honor de las personas; Ley de Patrimonio Histórico Español de 25 de Junio de 1985; Ley orgánica de Protección de Datos de Carácter Personal de 13 de Diciembre de 1999; Ley 2/2007 de 12 de Abril de Archivos y Patrimonio Documental de la Junta de Extremadura y Reglamento de Archivos Eclesiásticos de 1976; Normativa de Archivos Eclesiásticos de la Provincia Eclesiástica de Mérida-Badajoz y las disposiciones que en materia de Archivos dicte la Conferencia Episcopal Española. La descripción de los fondos del Archivo -el Seminario Diocesano de San Atón, los Colegio-Seminarios Menor San Benito y Nuestra Señora de la Coronada, el Seminario de Elvas-Olivenza, el fondo musical y el de colecciones (fotografías y monedas)-, realizada según las normas ISAD $(G)$ se incluye en el apéndice del artículo.

\section{Archivos de seminarios e investigación histórica: el archivo del Seminario San Atón de Badajoz}

La estructura que configura el cuadro de clasificación para este tipo de archivos, y muy especialmente, la del Seminario San Atón, nos permite resaltar las series documentales más relevantes para estas entidades. Veamos ahora estas cuestiones, tanto desde una perspectiva global, es decir, la que se refiere al conjunto de archivos de seminarios que constituyen la Iglesia, como desde una visión muy particular, la del Archivo del Seminario San Atón de Badajoz.

Las series documentales que están intrínsecamente relacionadas con el profesorado y el alumnado nos aportan en estos cuadros de clasificación datos de suma importancia para el conocimiento exhaustivo de tareas educativas. Estas series, en todos los archivos de semina- rios, son fuente de contenidos muy relevantes para la historia, muy concretamente para la educación y especialmente en los siglos XVII-XVIII, puesto que en algunas poblaciones españolas, sirva de ejemplo la ciudad de Badajoz, fueron exclusiva fuente de formación universitaria cuando esta institución aún no había sido concebida. Por ello, sus archivos recogen datos educativos y pedagógicos únicos. No debemos olvidar que en caso pacense el Seminario de San Atón de Badajoz fue sede de la primera Universidad en Extremadura, dependiente de la Universidad de Salamanca, por Real Cédula de Carlos IV, de 17 de agosto de 1793, estableciéndose en el mismo cuatro facultades: Arte, Teología Escolástica y Moral, Derecho Civil y Derecho Canónico. Este hecho conlleva a la existencia de documentos que dan debida prueba de un proceso formativo que involucró a personas que en muchos casos no llegaron a ser sacerdotes y utilizaron nuestro Seminario como herramienta de enseñanza universitaria. Debemos resaltar la importancia de este tipo de documentación en nuestro archivo dado su carácter único.

Además, y relacionadas con las cuestiones educativas los archivos de seminarios transmiten datos biográficos de sumo interés, recogidos en libros de informaciones y expedientes personales de profesores y alumnos. Si tenemos en cuenta el papel formativo, único en algunos casos, de estas instituciones podemos entender como por sus instalaciones han pasado personajes singulares para la historia de nuestro país. En el caso del Seminario de Badajoz, destacan entre otros don Mateo Delgado Moreno, Arzobispo-obispo de Badajoz; don Manuel Godoy, Príncipe de la paz; don José María Calatrava, Presidente del Consejo de Ministros y del Tribunal Supremo; don Fernando Ramírez Vázquez, obispo de Badajoz; don Vicente Barrantes Moreno, ilustre bibliófilo y poeta; don Antonio Senso Lázaro, obispo de Astorga; don José López Prudencio, insigne escritor; don Antonio Reyes Huertas, gran novelista; don Enrique Delgado Gómez, obispo de Pamplona; don Manuel Fernández Conde, obispo de Córdoba y don Amadeo Rodríguez Magro, actual obispo de Plasencia. Sin lugar a duda, los datos que pueden ser extraídos de cada uno de estos personajes en nuestro archivo forman parte de las biografías que sobre muchos de ellos existen ya, y sobre otras que pudieran acometerse en un futuro.

Otra de las cuestiones que puede ser debidamente analizada, según los datos que nos facilitan estos cuadros de clasificación es la relativa a la espiritualidad del momento, dado que el número de expedientes de alumnos por año 
puede ser considerado como un dato clave en este tema, es decir, los años de más alumnos en los seminarios españoles son entendidos como épocas de mayor esplendor religioso, en detrimento de los años en que el número de vocaciones es menor. Este hecho se constata nuevamente en nuestro Seminario de Badajoz, siendo el siglo XVII-XVIII el periodo más ampliamente respaldado con un nutrido número de expedientes personales.

Otra de las cuestiones a resaltar en los seminarios es su patrimonio, debiendo hacer especial hincapié en el artístico. Sus archivos recogen documentación de estas piezas, muchas de ellas sacramentales (cálices, patenas, crucifijos, casullas, manteles bordados, etc), algunas otras artísticas (cuadros y esculturas), otras bibliográficas (libros). Los archivos dan fe de cada una de estas posesiones de una manera detallada, aportando datos que van más allá de los puramente testamentarios, que recogen la procedencia de estas obras, como son datos artísticos, bibliográficos y nominativos, como en las donaciones, información acerca de los benefactores. En el caso del Seminario de Badajoz haremos especial alusión a las cuestiones bibliográficas, dado que hemos localizados legados y catálogos de donaciones de libros de obispos de singular relevancia, sirvan de referencia Solís y Gragera y Soto Mancera, pero también a posesiones que fueron donadas por vía testamentaria como las que pertenecen a la obra pía de Arias de Hoces o Pedro Casas Guerrero.

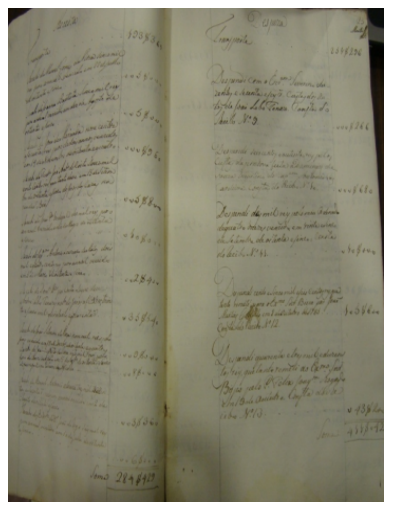

Figura 4. Libro de cuentas del Seminario de Yelbes (1801-1808)

Ubicamos en último lugar, no por su menor importancia sino por su heterogeneidad, las cuestiones histórico-culturales. En el marco en el que nos desenvolvemos son muchos y variados, los contenidos relativos a la historia y a la cultura que se ubican en los archivos de seminarios: expedientes de músicos, planos, sellos, mapas, monedas, medallas, etc.
El archivo del Seminario de San Atón da prueba de todos ellos. Posee un interesante fondo musical que se constituye de partituras de música sacra y profana, algunas de ellas exclusivas de nuestro Seminario, como piezas creadas para ser interpretadas en alguna solemnidad, especialmente la de su patrón. Además de una pequeña biblioteca auxiliar relativa a la materia integrada por libros y revistas.

Su colección de monedas, ubicada en la sección fija del archivo, ha sido considerada por algunos expertos como una de las mejores a nivel privado conservadas en España. Sus más de 5.000 piezas, donadas, como mencionamos anteriormente, en su gran mayoría por el obispo Soto Mancera en 1910, se remontan al siglo III a. C. Muchas de ellas tesoros únicos que han encontrado en una incorrecta acuñación un valor que perdurará a lo largo de los siglos. Completada también por una pequeña biblioteca auxiliar en la materia, así como por los catálogos que de su estudio, aún en su etapa inicial, está generando.
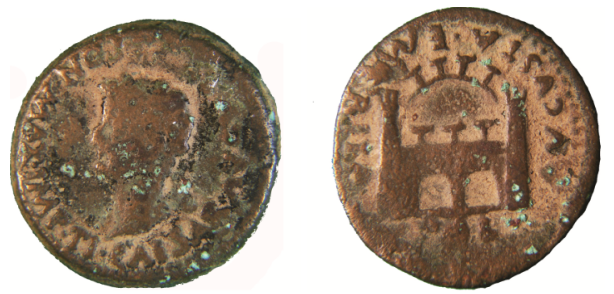

Figura 5. Sección Numismática del Archivo Seminario San Atón de Badajoz

En también singular una pequeña colección de medallas, de los siglos XVIII al XX, que recoge las figuras de reyes, papas y santos.

$Y$ muy destacable también la colección de sellos del siglo $\mathrm{XX}$, donación del obispo de la diócesis pacense $D$. Doroteo Fernández que, junto con la de fotografías, complementan el archivo del Seminario.

\section{Conclusiones}

Los archivos de la Iglesia católica conservan y transmiten una importantísima parte de la cultura de todos los tiempos. En especial, los archivos de los seminarios custodian la documentación producida y recibida por estas entidades en sus actividades educativas y pastorales. Como prueba de ello, el Seminario san Atón de Badajoz custodia documentos desde el s. XV intrínsecamente relacionados a sus actividades formativas. Por tanto, debemos tener en estos archivos un referente clave y primordial a la hora de emprender estudios relacionados con la 
educación, muy especialmente durante los siglos XVI al XVIII. Aquellos que acometan investigaciones sobre el panorama educativo de la sociedad extremeña desde el siglo XVI tienen en el archivo del Seminario de Badajoz documentación única que aportará a sus trabajos cimientos de suma relevancia para la consecución satisfactoria de los mismos.

Remarcar la necesidad inminente de que en todos los archivos que componen la Iglesia católica se efectúen sin más dilación tareas de ordenación y clasificación de sus fondos que, no sólo pongan a la luz documentación hasta la fecha inédita, sino que eviten su destrucción, es decir, la lapidación de la historia eclesiástica española. El Seminario de san Atón consciente de este hecho trabaja en salvaguardar su patrimonio y ejecuta tareas que van a permitir poner al servicio de la sociedad la documentación de sus archivos.

Destacar que los contenidos más ampliamente representados en los archivos de Seminarios son los relacionados con: educación, patrimonio y espiritualidad. Nuevamente, el Seminario de San Atón, respalda esta afirmación. En su archivo encontramos una voluminosa documentación relativa a estas cuestiones, permitiéndonos afirmar que todos aquellos que emprendan estudios relacionados con la educación en Extremadura, desde el siglo XVI al XIX, debieran consultar nuestra documentación para obtener una visión amplia de la situación formativa y pedagógica de Extremadura en dicho periodo. Al acoger el Seminario durante el siglo XVIII la primera Biblioteca pública y el único centro de enseñanza superior de Badajoz, así como el primer centro universitario de Extremadura, se custodian en nuestros archivos documentos vitales para el análisis de estas cuestiones.

\section{Referencias}

Aldea Vaquero, Q.; Marín Martínez, T.; Vives Gatell, J. (1972). Diccionario de Historia Eclesiástica. Madrid: Instituto Enrique Florez, 1972. 82-85.

Altamira, L. (1943). El seminario conciliar de nuestra señora de Loreto: Córdoba: Colegio Mayor de la Universidad de Córdoba.

Anasagasti, P. (1915). Seminario Conciliar de Vitoria. Vitoria.

Asociación de Archiveros de la Iglesia. Clasificación de archivos, 1997.

Barrantes, Vicente. Prólogo. // Barrantes Vicente. Discursos Patrios..., Badajoz, 1870, 47-48.

Blanco Cotano, M. (1998): El primer centro universitario de Extremadura: Badajoz 1973: historia pedagógica del Seminario de San Atón. Cáceres: Universidad de Extremadura.

Blanco Cotano, Mateo (1998). El primer centro universitario de Extremadura. Badajoz 1973: Historia pedagógica del
Seminario de San Atón. Cáceres: Universidad de Extremadura.

Bonet, J. Ma . (dir.) (2001). Guía de los Archivos de la Iglesia en España. Barcelona: Asociación de Archiveros de la Iglesia; Ministerio de Educación, Cultura y Deporte, 2001. http://www.muc.es/archivos/docs/archivosiglesia. pdf. Es una clasificación y detallada aunque delimitada en el marco de la propia Asociación.

Brown, P. (1990). La Antigüedad Tardía. // Ariès P. y Duby G. (eds.). Historia de la vida privada I. Madrid: Taurus, 1990. 230-303.

Cartas Reales. Archivo Capitular de Badajoz, Tomo $1^{\circ}, \mathrm{n}^{\circ}$ 20.

Código de Derecho Canónico de 1917 (1999). Madrid: BAC, 1999.

Código de Derecho Canónico de 1983 (1992). Madrid: Trivium, 1992.

Concilium Aquisgranense, I, 135.

Concilium Tridentinum, Diariorum, Actorum, Epistularum, Tractatuum nova Collectio IX, 1901. 628-630.

Díaz, J.R. (1991). El seminario conciliar de San Ildefonso de Toledo: cien años de historia (1889-1989). Toledo.

Fernández Conde (1948). España y los seminarios tridentinos. Madrid, 1948.

García García, Antonio (dir.) (1990). Synodicon Hispanum. Madrid: BAC.

García Hernando, J. (1959). El seminario conciliar de Segovia: antecedentes históricos. Instituto Diego de Colmenares. Segovia.

Hernández Corrales, A. (1992). El seminario conciliar de la Inmaculada del Archipiélago Canario (1777-1819). Barcelona: Universidad de Barcelona.

Hernández Figueiredo, J. R. (2004). El seminario conciliar de San Fernando de Orense (1804-1952). Historia de una institución de piedad y cultura. Roma: Auriae.

Iguacen Borau, D. (1999). Diccionario del patrimonio cultural de la Iglesia. Madrid: Encuentro, 1999. 140-143.

Mansilla Reoyo, D. (1954). El seminario conciliar de San Jerónimo de Burgos. // Hispania SacraVII; Pérez López, S. (1987). El seminario conciliar de San Torcuato: aspectos de una institución diocesana (1850-1865). Granada.

Martín Hernández, F. (1959). Los seminarios españoles en la época de los Borbones. // Hispania Sacra. XII, 357358.

Nunciatura Apostólica (1953). Carta circular de la Nunciatura Apostólica en España a los Reverendísimos Prelados sobre la reorganización de los archivos eclesiásticos (1929). // Hispania Sacra. VI (1953) 231-240.

Pontificia Comisión Para los Bienes Culturales de la Iglesia (1997). Carta circular "La Función Pastoral de los Archivos Eclesiásticos. Asociación de Archiveros de la Iglesia en España". Ciudad del Vaticano, 2 de Febrero de 1997.

Rops, Daniel (1970). Historia de la Iglesia, Madrid.

Rubio Merino, P. (1964). El Seminario Conciliar de San Atón (1664-1964). Madrid.

Rubio Merino, P. (1999). Archivística Eclesiástica: Nociones básicas. Sevilla: Guadalquivir. 53-153.

Rubio Merino, Pedro (1999). Archivística Eclesiástica: nociones básicas. Sevilla: Guadalquivir, 1999.

Seminario San Atón de Badajoz (1664-1672). Libro 1: Fundación Seminario (1664-1672).

Seminario San Atón de Badajoz (1783). Constituciones. Archivo del Seminario San Atón de Badajoz, Caja 1. 
Seminario San Atón de Badajoz (1849). Libro de Constituciones de... Archivo del Seminario San Atón de Badajoz, Caja 1.

Seminario San Atón de Badajoz (1863). Reglamento. Archivo del Seminario San Atón de Badajoz , Caja 1.

\section{Apéndice: Organización de los fondos del Archivo}

DESCRIPCIÓN DEL FONDO SEMINARIO DIOCESANO DE SAN ATÓN: CUADRO DE CLASIFICACIÓN

\section{Area de identificación \\ 1.1. Código de Referencia: ES-ASMMB-0153}

1.2. Título(s): Archivo Seminario Metropolitano de Mérida-Badajoz (ASMMB).

1.3. Fechas Extremas: 1664-1946(f)/ 1464-1949 (p).

1.4 Nivel de Descripción: fondo.

1.5. Volumen y soporte: 140 libros y 131 cajas/papel-pergamino.

2. Area de contexto

2.1. Productor: Seminario de San Atón. Mérida-Badajoz.

2.2. Historia Institucional:

El Seminario se funda en el año de 1664 en unas casas pertenecientes al canónigo Dosma, cerca de la catedral. En el año 1733, se adquieren por el obispado otras casas frente al Palacio Episcopal, dado que el primer Seminario se había quedado pequeño, y en el año 1754 se instalan los colegiales. Posteriormente, en 1927, adaptándose a las vicisitudes de los tiempos, el Seminario ocupó un terreno a las afueras de la ciudad, que había sido adquirido en la Cañada Sancha Brava, donde se encuentra en la actualidad.

El archivo del Seminario de San Atón se crea a la vez que se instituye la entidad, el 26 de Mayo de 1664, siendo obispo don Jerónimo Rodríguez de Valderas, según consta en el título 27 de las Constituciones que se aprobaron para la vida cotidiana del centro.

2.3. Historia Archivística:

El fondo documental está formado por la documentación producida y recibida por el Seminario de San Atón y otras instituciones (colegiosseminarios), dependientes de él, (hoy desaparecidas), en el trascurso de su actividad académica y pastoral. Dividido en tres secciones, de acuerdo a las Constituciones del centro y al Reglamento interno; así como a la reglamentación canónica. El documento más importante por su valor histórico es el Libro Fundacional fechado en el año 1664, que incluye las primeras constituciones del Seminario; si bien el documento más antiguo es una escritura de censo de 1464, de las obras pías que se agregaron a él para su mantenimiento.

3. Area de contenido y estructura

3.1. Alcance y Contenido: las series más importantes por su valor histórico y por el volumen documental que representan en el archivo son las relativas a informaciones, expedientes de ingresos de seminaristas, becas, constituciones, normativas, reglamentos y obras pías.

3.2. Valoración, Selección y Eliminación: documentación histórica de conservación permanente.

3.3. Nuevos Ingresos: realizados por el mismo centro por medio de transferencias periódicas.

3.4. Organización: cuadro de clasificación

\begin{tabular}{|c|c|c|c|}
\hline Clasificación & Fechas & C & $L$ \\
\hline \multicolumn{4}{|l|}{ 1.GOBIERNO } \\
\hline $\begin{array}{l}\text { Libro Fundación Seminario } \\
\text { Libro Doc Obispo y Obispado }\end{array}$ & $1734-1735$ & & 2 \\
\hline $\begin{array}{l}\text { Libro Doc. Obispo y Obispado } \\
\text { Libro Bulas y Doc. Obispado }\end{array}$ & 1709 & & 1 \\
\hline Bulas & 1865 & 1 & \\
\hline Libro Decretos Episcopales & $1867-1868$ & & 1 \\
\hline Constituciones & 1783-1797 & & \\
\hline Libro de Constituciones & 1849 & & 1 \\
\hline Libro Inventario Obispado & 1734 & & 1 \\
\hline Libro Actas de Visitas & $1900-1906$ & & 1 \\
\hline Reglamentos & 1863 1926 & & \\
\hline \multicolumn{4}{|l|}{ 1.2.Documentación Rectorado } \\
\hline Libro de Actas Seminario & 1853-1934 & & 4 \\
\hline Actas & 1868 & & \\
\hline Libro de Actas Académicas & $1909-1918$ & & 1 \\
\hline Libro de Actas Misión del Clero & $1922-1923$ & & 1 \\
\hline
\end{tabular}

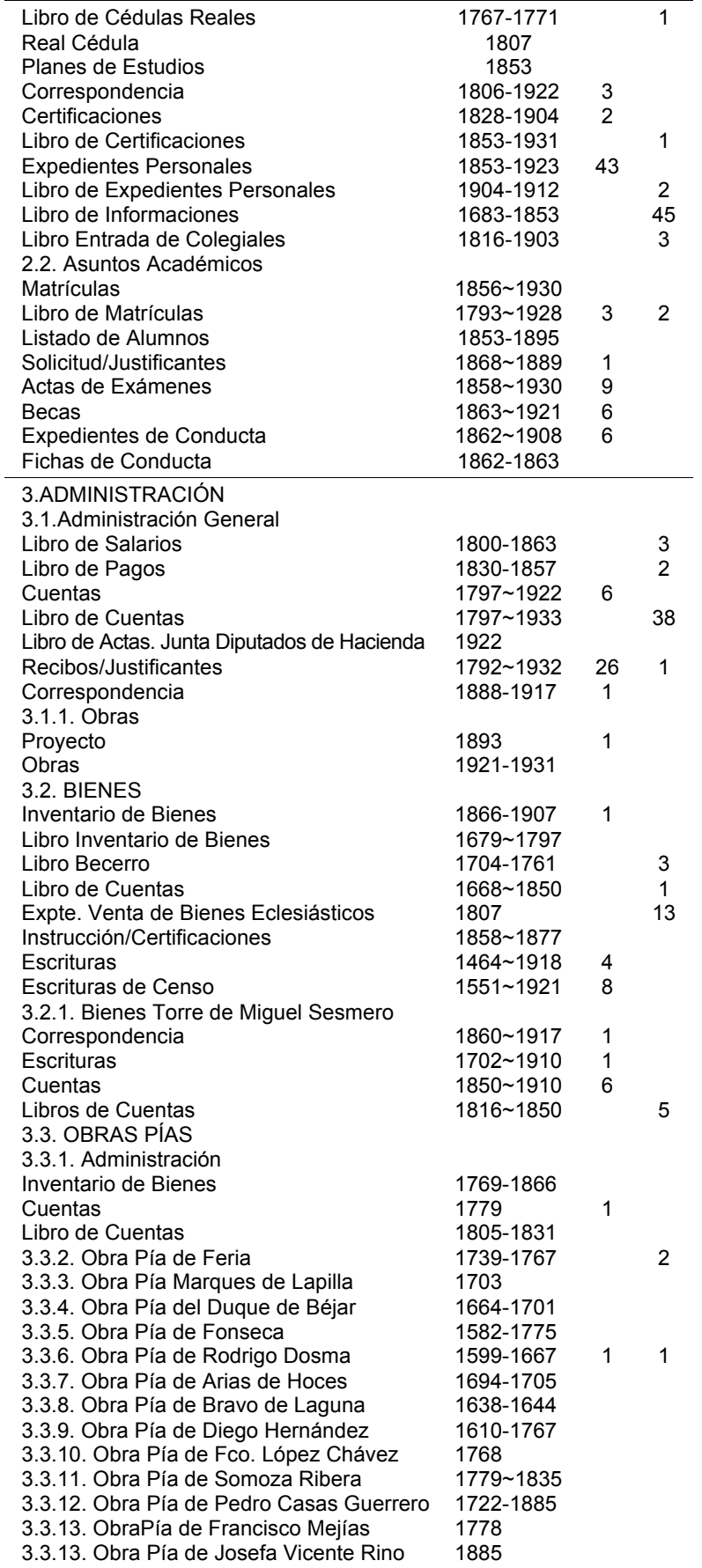

4. Area de contenidos de acceso y utilización

4.1. Condiciones de Acceso: la consulta del fondo documental es libre y gratuita, sólo restringida en lo referente al derecho de intimidad y honor de las personas; Ley de Patrimonio Histórico Español, de 25 de Junio de 1985; Ley Orgánica de Protección de Datos de Carácter Personal, de 13 de Diciembre de 1999; Ley 2/2007, de 12 de Abril de Archivos y Patrimonio Documental de la Junta de Extremadura y Reglamento de Archivos Eclesiásticos de 1976; Normativa de Archivos Eclesiásticos de la Provincia Eclesiástica de MéridaBadajoz y las disposiciones que en materia de archivos dicte la Conferencia Episcopal Española.

4.2. Servicio de Reproducción: sí.

4.3. Lengua/ Escritura: latín; castellano /cortesana y procesal; otros.

4.3. Características Fisicas y Requisitos Técnicos: Consulta original. Documentación deteriorada fuera de consulta.

4.4. Instrumentos de Descripción: primer inventario realizado por equipo del Seminario; cuadro de clasificación e inventario realizado por María del Carmen Fuentes Nogales y Guadalupe Pérez Ortiz.

5. Area de documentación asociada 
5.1.Existe ncia y Localización de Documentos Originales: Archivo Capitular de Mérida-Badajoz; Archivo Diocesano de Mérida-Badajoz; Archivo Diputación de Badajoz; Archivo Histórico Provincial de Badajoz; Archivo Municipal de Badajoz.

5.2. Existencia y Localización de Copias: no.

5.3. Unidades de Descripción Relacionadas: Archivos Eclesiásticos de la Archidiócesis de Mérida-Badajoz.

5.4. Nota de publicación. Son innumerables las publicaciones realizadas. Destacamos:

Barrena Gómez, D. El Seminario Archidiocesano de San Atón en la Cañada de Sancha Brava, (1927-2004). Badajoz, 2004.

Blanco Cotano, M. El Primer Centro Universitario de Extremadura: Badajoz, 1793. Historia Pedagógica del Seminario de San Atón. Cáceres: Universidad de Extremadura, 1998.

Gomez Villafranca, R. Gabinete Numismático del Seminario Conciliar de San Atón. Badajoz, 1910.

Rubio Merino, P. El Seminario Conciliar de San Atón. 1664-1964. Madrid, 1964.

Solar Y Taboada, A. El Seminario San Atón de Badajoz. Badajoz: Arqueros, 1948.

6. Area de notas

6.1. Notas

4. Area de control de descripción

4.1. Nota del Archivero

4.2. Regla o Norma: ISAD (G).

4.3. Fecha de la Descripción: junio de 2013

DESCRIPCIÓN DEL FONDO COLEGIO-SEMINARIO MENOR SAN BENITO DE VILLANUEVA DE LA SERENA

Volumen/Soporte: 2 libros-4 cajas/ papel.

Fechas Extremas: 1884-1917.

Historia Institucional: bajo el episcopado de don Fernando Ramírez, se adecúa para seminario menor de la Diócesis el Palacio de los Priores de Magacela, en Villanueva de la Serena, fundamentalmente, para atender a las vocaciones de la zona de la Serena que se encontraban demasiado distantes de la capital (1884-1892).

Historia Archivística: documentación es muy escasa, destacando dos libros de matrículas.

Organización:

\begin{tabular}{lccc}
\hline Clasificación & Fechas & Caja & Libro \\
\hline Libro de Matrículas & $1884 \sim 1891$ & 2 & 2 \\
Solicitudes & $1884-1891$ & 2 & \\
Notas & $1884-1885$ & 2 & \\
Escrituras & $1884-1886$ & & \\
Cuentas & $1884-1892$ & & \\
\hline
\end{tabular}

Estado de Conservación: buena.

Instrumentos de Descripción: inventario.

DESCRIPCIÓN FONDO SEMINARIO MENOR NUESTRA SEÑORA DE LA CORONADA. VILLAFRANCA DE LOS BARROS

Volumen/Soporte: 2 libros-2 cajas/ papel.

Fechas Extremas: 1923-1939.

Historia Institucional: bajo el episcopado de don Ramón Rodríguez se compra una casa en la localidad de Villafranca de los Barros para instalar en ella un seminario menor, que se mantendría abierto desde 1924 a 1939.

Historia Archivística: la documentación es muy escasa, se conserva un libro de cuentas y uno de notas.

Organización:

\begin{tabular}{lccc}
\hline Clasificación & Fechas & Caja & Libro \\
\hline Libro de Notas & $1929-1930$ & & 1 \\
Libro de Cuentas & $1923-1926$ & 2 & 1 \\
Cuentas & $1925-1939$ & &
\end{tabular}

Estado de Conservación: buena.

Instrumentos de Descripción: inventario.

\section{DESCRIPCIÓN FONDO SEMINARIO DE ELVAS-OLIVENZA}

Volumen/Soporte: 6 Libros- 1 caja/papel.

Fechas Extremas: 1784-1909.

Historia Institucional: en la ciudad de Yelbes se estableció un seminario siguiendo las disposiciones del Concilio de Trento; se le adjudi- caron, para su funcionamiento, diferentes bienes de un convento de religiosas clarisas sujetos a la autoridad episcopal diocesana perteneciente al término y jurisdicción de Olivenza. Por la insuficiencia de sus rentas no pudo subsistir demasiado tiempo y el obispo de Yelbes, para poder llevar a cabo la instrucción de sus diocesanos erigió una cátedra en diferentes pueblos de su territorio creando una de Moral y otra de Instituciones Canónicas en Olivenza.

Historia Archivística: hemos optado por disponer en un mismo fondo documental los fondos del Colegio Seminario de Olivenza y los Seminarios de Yelbes y Elvas, dado que la documentación está relacionada. Se componen, principalmente, de libros de cuentas.

Alcance y Contenido: la documentación más importante desde el punto de vista histórico es la relativa a informes, cuentas y censos. Permite ampliar la contextualización geográfica con el país vecino, Portugal.

Organización:

\begin{tabular}{lccc}
\hline Clasificación & Fechas & Caja & Libro \\
\hline 1. SEMINARIO ELVAS & $1784-1802$ & & \\
Libro de Cuentas & $1794-1802$ & 1 & 1 \\
Libro de Foro de Trigo & $1790-1791$ & & 1 \\
Libro de Censos & $1799-1801$ & & 1 \\
Informe Seminario & $1797-1868$ & & 1 \\
Cuentas & $1801-1808$ & & 1 \\
2. SEMINARIO YELBES & $1817-1818$ & & \\
Libro de Cuentas & $1793-1821$ & & \\
Libro de Cuentas & $1849-1909$ & & \\
3. OLIVENZA & & & \\
Libro de Cuentas & & \\
Correspondencia & &
\end{tabular}

Lengua: castellano, portuguesa.

Estado de Conservación: bueno.

Instrumentos de Descripción: inventario.

\section{DESCRIPCIÓN DEL FONDO MUSICAL}

Volumen/Soporte: 25 cajas/ papel.

Fechas Extremas: siglos XIX-XX.

Historia Archivística: el fondo musical contiene partituras de música sacra y profana.

Alcance y Contenido: está compuesto de 90 partituras distribuidas en 17 cajas; complemento a dichos documentos se conservan varias revistas de música.

Organización:

\begin{tabular}{lcc}
\hline Clasificación & Fechas & Caja \\
\hline Partituras & Siglos XIX-XX & 17 \\
Revista Tesoro Sacro & $1950-1973$ & 5 \\
Revista Polifónica & $1943-1953$ & 2 \\
Revista La Música & $1958-1973$ & 1 \\
\hline
\end{tabular}

Estado de Conservación: bueno.

Instrumentos de Descripción: inventario.

FONDO COLECCIONES

\begin{tabular}{lc}
\hline Clasificación & Fechas \\
\hline 1. Fotografías & Siglos XIX-XX \\
2. Monedas & Siglo IV (a.d.C)-XIX \\
\hline
\end{tabular}

Desde hace más de 100 años, el Seminario Metropolitano de San Atón conserva y custodia una de las mejores colecciones privadas de Extremadura y casi de España. Las casi 5000 piezas que la componen, aportan a la Historia de la Institución, de Badajoz y de Extremadura, un legado patrimonial único. El Gabinete Numismático, como así se denominó, fue producto de la gran formación humanística de Don Félix Soto Mancera, Obispo de Badajoz entre 1905 y 1910; a dicha colección se irán añadiendo donaciones posteriores hasta alcanzar la inestimable cantidad de piezas mencionadas anteriormente. Sin duda, constituyen un legado único que aporta interesantes datos en la investigación por ser la numismática, como la archivística, ciencia auxiliar de la historia.

Enviado: 2014-03-26. Segunda versión: 2014-07-14 Aceptado: 2014-07-14. 